\title{
Connecting heterocycles via a catalyzed lithiation ${ }^{\dagger}$
}

\author{
Francisco Foubelo, Daniel García, Benjamín Moreno and Miguel Yus* \\ Departamento de Química Orgánica and Instituto de Síntesis Orgánica (ISO), Facultad de \\ Ciencias, Universidad de Alicante, Apartado 99, E-03080 Alicante, Spain \\ E-mail:yus@ua.es
}

\section{Dedicated to Professor Alan R. Katritzky on the occasion of his 80th birthday}

\begin{abstract}
Recent results in the field of the arene-catalyzed lithiation of different heterocycles are presented in this account. This process allows the transformation of several heterocyclic systems into a series of functionalized organolithium compounds by a regioselective ring-opening of the heterocycle. The further reaction of the mentioned organolithium intermediates with different electrophiles affords, after hydrolysis, the corresponding functionalized molecules. Some of these products, derived from carbonyl compounds can be easily cyclized again to give a new series of heterocycles in which the electrophilic fragment has been incorporated to the corresponding starting heterocycle.
\end{abstract}

Keywords: reductive ring-opening; phthalans; DTBB-catalyzed lithiation; electrophilic substitution; substituted naphthalenes, substituted biphenyls, substituted binaphthyls

\section{Introduction}

Functionalized organolithium compounds ${ }^{1}$ can be achieved following classical procedures (i.e., halogen-lithium exchange or tin-lithium transmetallation) ${ }^{2}$ or, in some cases, through new methodologies, among them the reductive opening of different appropriate oxygen-, nitrogenand sulfur-containing heterocycles. ${ }^{3}$ The interest of functionalized organolithium compounds lies in their applicability in organic synthesis, due to the fact that by reaction with electrophiles, polyfunctionalized molecules are obtained in a single synthetic operation. Lithium metal itself or lithium in the presence of a stoichiometric or catalytic amount of an arene [naphthalene, 4,4'-ditert-butylbiphenyl (DTBB), biphenyl, 1-(N,N-dimethylamino)naphthalene being the most commonly used] have been used as the lithiating reagents in the reductive opening of

\footnotetext{
${ }^{\dagger}$ Presented by M. Y. as an invited lecture at the 5th Eurasian Meeting on Heterocyclic Chemistry (EAMHC-5), Kuwait March 2008.
} 
heterocycles. ${ }^{3}$ Only small heterocycles (three and four membered-rings), which are prone to release the strain energy, and heterocycles with activated bonds can undergo a reductive opening lithiation. For instance, benzylic carbon-oxygen bonds are susceptible to reductive cleavage by means of a lithiating reagent to generate benzylic organolithium compounds through a SET process. Phthalan $(\mathbf{1}, n=1)$ is a special kind of cyclic benzyl ether and is opened reductively with an excess of lithium in the presence of a sub-stoichiometric amount of $\mathrm{DTBB}^{4}$ or naphthalene ${ }^{5}$ to give the dianionic intermediate 4. Thus, after a first electron transfer to phthalan $\mathbf{1}$, the radical anion $\mathbf{2}$ is formed and it decomposes to give a more stable radical anion $\mathbf{3}$, which after a second electron transfer, leads to the dilithium derivative $\mathbf{4}$ in almost quantitative yield. The reaction of $\mathbf{4}$ with different electrophiles allows the preparation of functionalized alcohols $\mathbf{5}$ (Scheme 1). The intermediate $\mathbf{4}$ has also been transformed into the corresponding functionalized organozinc derivative by a lithium-zinc transmetallation process with zinc bromide, and its reaction with allylic bromides, ${ }^{6}$ aryl halides in the presence of palladium, ${ }^{7,8}$ electrophilic olefins $^{9,10}$ and acylating reagents was studied. Diols $\mathbf{5}$ derived from the reaction of intermediate 4 with carbonyl compounds $\left(\mathrm{E}^{+}=\mathrm{R}_{1} \mathrm{R}_{2} \mathrm{CO}\right)$, are easily cyclized under acidic conditions to give the corresponding six-membered benzo-condensed cyclic ethers 6 (Scheme 1). The same process starting from isochroman $(\mathbf{1}, n=2)$ leads to functionalized alcohols 5 with $n=2$ and sevenmembered heterocycles $\mathbf{6}^{11}$

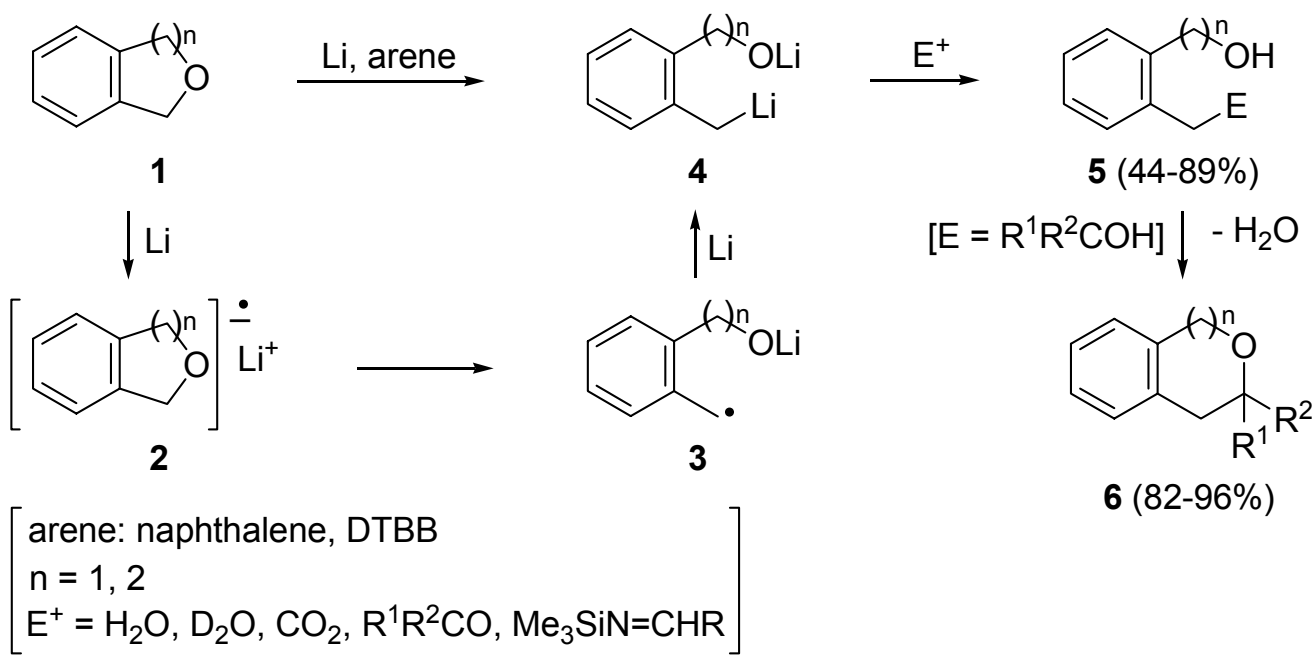

\section{Scheme 1}

With these antecedents, we considered it of interest to study the reductive opening lithiation of different heterocycles with benzylic carbon-oxygen and carbon-sulfur bonds. In addition, the regiochemistry of the reductive opening lithiation of different non-symmetrical phthalan derivatives by an arene-catalyzed lithiation would be studied also in order to know how the aromatic moiety of these compounds affects the process. 


\section{Results and Discussion}

\subsection{Lithiation of 2,7-dihydrobenzothiepin}

The treatment of 2,7-dihydrodibenzothiepin (7) with an excess of lithium and a catalytic amount of DTBB at $-78{ }^{\circ} \mathrm{C}$ leads to the intermediate 8 , which reacts with carbonyl compounds to give the corresponding alkoxides, 9, and after acidic hydrolysis to the sulfanyl alcohols, 10. However, when alkoxides 9 are stirred at room temperature in the presence of an excess of the lithiating mixture, the remaining benzylic carbon-sulfur bond is cleaved leading to new intermediates 11, which after reaction with a second electrophile and final hydrolysis with water lead to polyfunctionalized compounds 12 (Scheme 2). ${ }^{12,13}$<smiles>c1ccc2c(c1)CSCc1ccccc1-2</smiles>

7<smiles>[R]C([R])(O)Cc1ccccc1-c1ccccc1CS</smiles>

10 $(47-82 \%)$

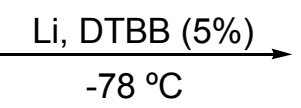<smiles>C[13CH][13CH]</smiles>

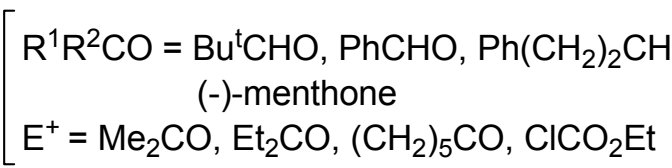

9<smiles>[R]C([R])(O)Cc1ccccc1-c1ccccc1CF</smiles>

$12(35-46 \%)$

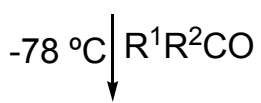<smiles>[R]C([R])(O)Cc1ccccc1-c1ccccc1C[Si]</smiles>

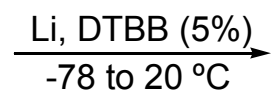<smiles>[R]C([R])(O)Cc1ccccc1-c1ccccc1CCl</smiles>

11 1. $\mathrm{E}^{+},-78^{\circ} \mathrm{C}$
2. $\mathrm{H}_{2} \mathrm{O}$

1

\section{Scheme 2}

\subsection{Lithiation of 2,7-dihydrodinaphthoxepine and -thiepine}

The reaction of 2,7-dihydro-3H-dinaphtho[2,1-c:1',2'-e]oxepine $(\mathbf{1 3}, \mathrm{Y}=\mathrm{O})$ and -thiepine (13, $\mathrm{Y}=\mathrm{S}$ ) with an excess of lithium and a catalytic amount of DTBB, under the same reaction conditions shown in Scheme $1\left(\mathrm{THF},-78^{\circ} \mathrm{C}\right.$ ), gave, after treatment with different electrophiles at the same temperature, and final hydrolysis, the corresponding compounds $\mathbf{1 7}$, resulting from a double condensation at both benzylic positions involving the intermediate 16 (Scheme 3). In contrast to the behavior observed for the starting material 7, in the case of compounds 13 it 
seems that after the first reductive ring-opening, the organolithium intermediate $\mathbf{1 4}$ initially formed suffers a rapid second lithiation to give the dilithium compound 16, which can survive under the essayed conditions until the addition of the electrophile. In order to avoid the mentioned second lithiation we used the less active stoichiometric version of the arene-promoted lithiation. Thus, treatment of the starting materials $\mathbf{1 3}$ with a THF solution of lithium naphthalene (1:2.2 molar ratio) in THF at $-78{ }^{\circ} \mathrm{C}$, followed by reaction with an electrophile at the same temperature gave, after hydrolysis under acidic conditions, the corresponding monosubstituted products $\mathbf{1 5}$ (Scheme 3 ). Chiral starting materials $\mathbf{1 3}$ are accessible from commercially available $(R)$ - or $(S)$-binaphthol $(>99 \% e e)$, thus applying this methodology it is possible to prepare enantiomerically pure binaphthyl derivatives of general structure $\mathbf{1 5}$ and $\mathbf{1 7} .^{13,14}$

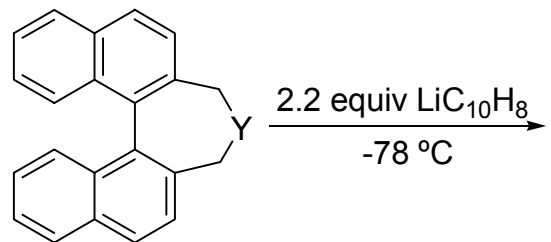

13

Li, DTBB $(5 \%)$
$-78^{\circ} \mathrm{C}$

16

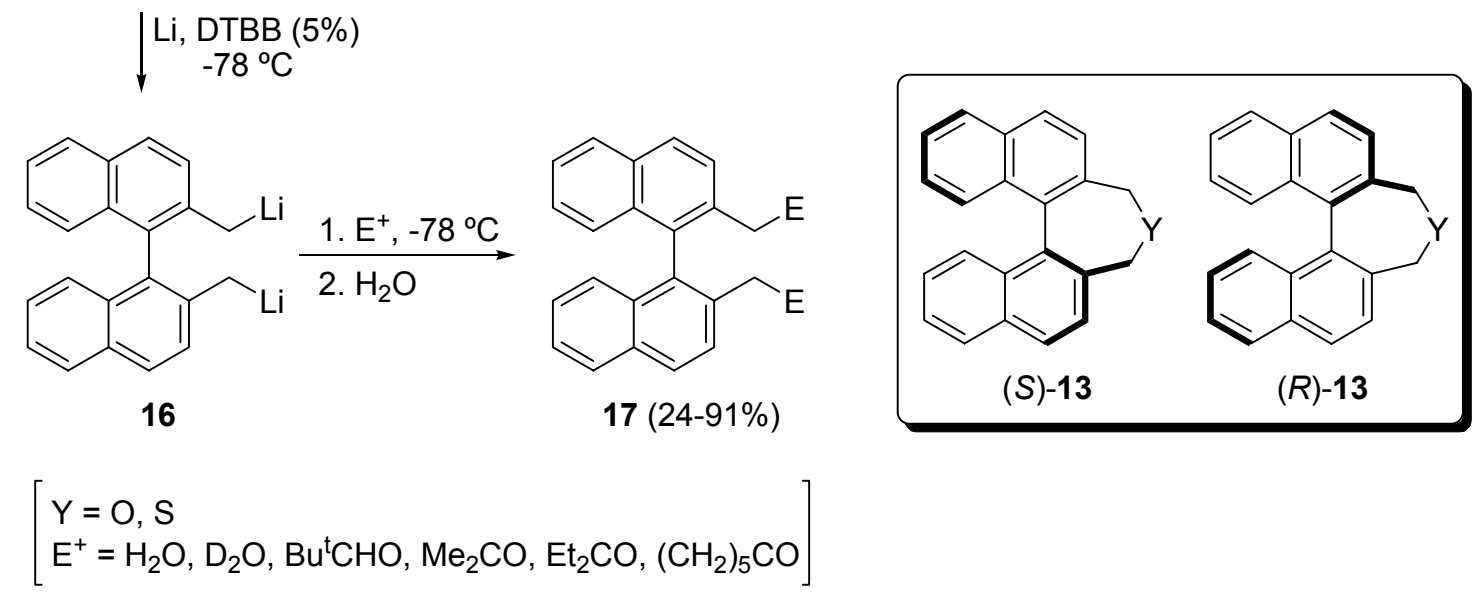<smiles>[Al]Cc1ccc2ccccc2c1-c1c(CCl)ccc2ccccc12</smiles>

14

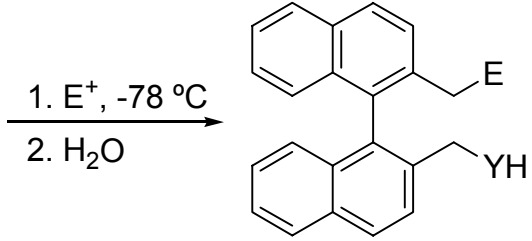

$15(36-81 \%)$

\section{Scheme 3}

\subsection{Lithiation of $1 \mathrm{H}, 3 \mathrm{H}$-benzo[de]isochromene}

The reaction of $1 H, 3 H$-benzo[de]isochroman (18) with an excess of lithium (1/10 molar ratio) in the presence of a catalytic amount of DTBB $(5 \mathrm{~mol} \%)$ in THF at $-50{ }^{\circ} \mathrm{C}$ led, after $6 \mathrm{~h}$, to a solution of the dianion 19, which reacted with different electrophiles at the same temperature for 15 min yielding, after hydrolysis with water, the expected functionalized alcohols $\mathbf{2 0}$ (Scheme 4). A second lithiation took place leading to dianionic intermediate 22, when 19 reacted with a carbonyl compound as the first electrophile, and the resulting alcoholate was stirred at $0{ }^{\circ} \mathrm{C}$ for 2 $\mathrm{h}$ in the presence of the excess of the lithiating agent. The reaction of 22 with a second electrophile followed by hydrolysis with water led to 1,8-difunctionalized naphthalenes $\mathbf{2 3}$ (Scheme 4). Intramolecular dehydration of diols $\mathbf{2 0}\left(\mathrm{E}=\mathrm{R}^{1} \mathrm{R}^{2} \mathrm{COH}\right)$ by treatment with a catalytic 
amount of $p$-toluenesulfonic acid in the presence of $4 \AA$ molecular sieves in toluene at $110{ }^{\circ} \mathrm{C}$ gave the corresponding naphthoxepine $\mathbf{2 1}$ in high yields (Scheme 4). It is worthy to note that the whole process $\mathbf{1 8} \rightarrow \mathbf{2 1}$ represents the homologation of the starting heterocycle $\mathbf{1 8} .^{15}$

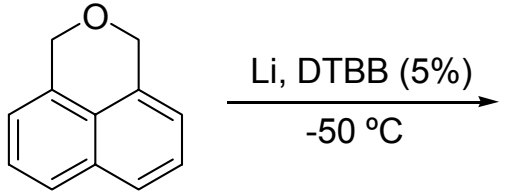

18

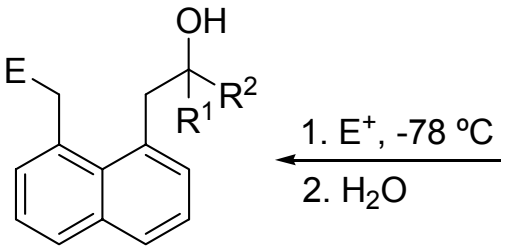

$23(41-58 \%)$<smiles>OCc1cccc2cccc(CCl)c12</smiles>

19

1. $\mathrm{R}^{1} \mathrm{R}^{2} \mathrm{CO},-50^{\circ} \mathrm{C}$
2. $0^{\circ} \mathrm{C}$<smiles>[R]C([R])(O)Cc1cccc2cccc(C[Hg])c12</smiles>

22

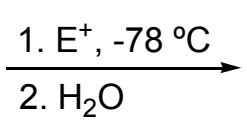<smiles>OCc1cccc2cccc(CF)c12</smiles>

$20(34-58 \%)$

$\mathrm{TsOH}$ cat.
$110^{\circ} \mathrm{C}$$\left[\mathrm{E}=\mathrm{R}^{1} \mathrm{R}^{2} \mathrm{COH}\right]$<smiles>[R]C1([R])Cc2cccc3cccc(c23)CO1</smiles>

$21(>95 \%)$

$$
\left[\begin{array}{l}
\mathrm{E}^{+}=\mathrm{H}_{2} \mathrm{O}, \mathrm{CO}_{2} \\
\mathrm{R}^{1} \mathrm{R}^{2} \mathrm{CO}=\mathrm{Bu}^{\mathrm{t}} \mathrm{CHO}, \mathrm{PhCHO}, \mathrm{Me}_{2} \mathrm{CO}, \mathrm{Et}_{2} \mathrm{CO},\left(\mathrm{CH}_{2}\right)_{5} \mathrm{CO},\left(\mathrm{CH}_{2}\right)_{7} \mathrm{CO},(-)-\text { menthone }
\end{array}\right]
$$

\section{Scheme 4}

\subsection{Lithiation of 1,3-dihydronaphtho[1,2-c]furan}

The starting 1,3-dihydronaphtho[1,2-c] furan (24) was prepared from commercially available 1,2dimethylnaphthalene in only two steps and in $49 \%$ overall yield. The reaction of compound $\mathbf{2 4}$ with an excess of lithium (1/10 molar ratio) in the presence of a catalytic amount of DTBB (5 mol\%) in THF at temperatures ranging from -78 to $-50{ }^{\circ} \mathrm{C}$ for $3 \mathrm{~h}$, followed by addition of different electrophiles $\left[\mathrm{H}_{2} \mathrm{O}, \mathrm{Bu}^{\mathrm{t}} \mathrm{CHO}, \mathrm{Me}_{2} \mathrm{CO},(\mathrm{EtO})_{2} \mathrm{CO}\right]$ at $-78^{\circ} \mathrm{C}$ and final hydrolysis, led to a mixture of functionalized alcohols 27 and 28 (Scheme 5). A 6:1 mixture (based on the study of the ${ }^{1} \mathrm{H}$ NMR spectrum of the crude product) of alcohols $27(\mathrm{E}=\mathrm{H})$ and $\mathbf{2 8}(\mathrm{E}=\mathrm{H})$ was obtained when $\mathrm{H}_{2} \mathrm{O}$ was used as electrophile. In the other cases, only products 27 were detected in the reaction crudes (NMR). Two reductive cleavages in the starting heterocycle $\mathbf{2 4}$ can occur under these reaction conditions: the major one leads to intermediate $\mathbf{2 5}$ and the minor one to intermediate 26, through the two possible benzylic carbon-oxygen bond cleavages. Diols $27(\mathrm{E}=$ $\mathrm{R}^{1} \mathrm{R}^{2} \mathrm{COH}$ ) and a lactone derived from intermediate $\mathbf{2 5}$ were the only reaction products isolated and characterized when $\mathrm{Bu}^{\mathrm{t}} \mathrm{CHO}, \mathrm{Me}_{2} \mathrm{CO}$ and $(\mathrm{EtO})_{2} \mathrm{CO}$ were respectively used as electrophiles (Scheme 5). ${ }^{16}$ 


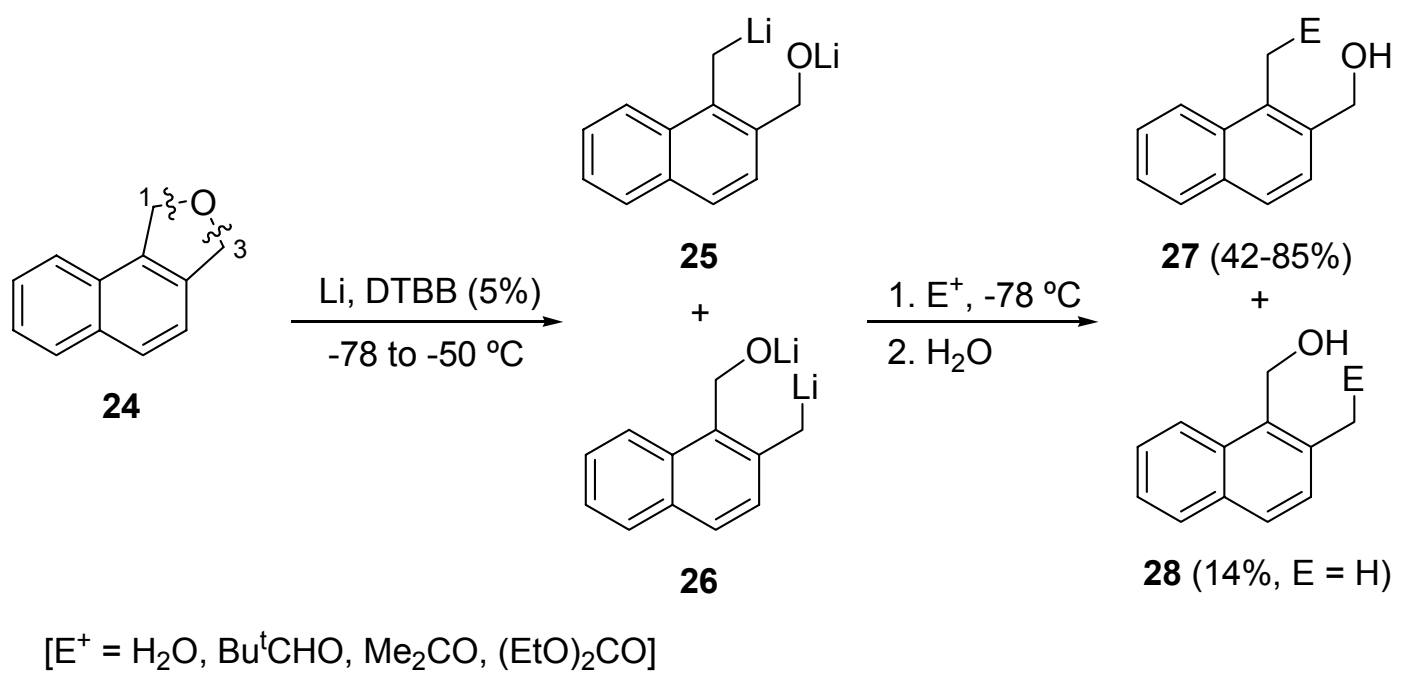

\section{Scheme 5}

\subsection{Lithiation of 4- and 5-phenylphthalans and 4- and 5-methoxyphthalans}

The reaction of phenylphthalans 29 and $\mathbf{3 2}{ }^{16}$ and methoxyphthalans $\mathbf{3 5}$ and $\mathbf{3 8}^{17}$ with an excess of lithium (1/10 molar ratio) in the presence of a catalytic amount of DTBB $(5 \mathrm{~mol} \%)$ in THF at $-78{ }^{\circ} \mathrm{C}$ for $3 \mathrm{~h}$, followed by addition of different electrophiles at $-78{ }^{\circ} \mathrm{C}$ and final hydrolysis, led exclusively to regioselectively functionalized biphenyls 31, 34, 37 and 40, respectively (Scheme 6). The structure of these compounds was elucidated based on NOESY experiments. In the case of 4-phenylphthalan (29) the reductive cleavage takes place at $\mathrm{C}(3)-\mathrm{O}$ benzylic bond leading to the intermediate 30, meanwhile, the reductive cleavage in 5-phenylphthalan (32) occurs at C(1)$\mathrm{O}$ benzylic carbon-oxygen bond giving the dianionic intermediate 33. On the other hand, 4methoxyphthalan (35) undergoes reductive cleavage at $\mathrm{C}(1)-\mathrm{O}$ benzylic carbon-oxygen bond and 5-methoxyphthalan (38) undergoes reductive cleavage at $\mathrm{C}(3)-\mathrm{O}$ benzylic carbon-oxygen bond, leading to the dilithium derivatives $\mathbf{3 6}$ and 39, respectively (Scheme 6). ${ }^{16,17}$

\subsection{Lithiation of 1,3-dihydrofurophthalan}

The reaction of 1,3-dihydrofurophthalan 41 with an excess of lithium (1/10 molar ratio) in the presence of a catalytic amount of DTBB $(2.5 \mathrm{~mol} . \%)$ in THF at $-78^{\circ} \mathrm{C}$ for $30 \mathrm{~min}$ and then for 2 $\mathrm{h}$ at $0{ }^{\circ} \mathrm{C}$, followed by addition of $\mathrm{H}_{2} \mathrm{O}$ and benzaldehyde as electrophiles at $-78{ }^{\circ} \mathrm{C}$ and final hydrolysis, led to a mixture of functionalized alcohols 44 and diols $\mathbf{4 5}$ in a regioselective manner (Scheme 7). According to these results, the intermediates $\mathbf{4 2}$ and $\mathbf{4 3}$ are involved in this process. Thus, after reductive cleavage of compound $\mathbf{4 1}$ (the four benzylic carbon-oxygen bonds are equivalent), the dianion $\mathbf{4 2}$ initially formed undergoes a second and selective reductive cleavage leading to the dialkoxide $\mathbf{4 3}$. When the reaction is performed for a longer reaction time or at higher temperatures in order to complete the transformation of intermediate $\mathbf{4 2}$ into $\mathbf{4 3}$, yields become significantly lower and variable amounts of 1,2,4,5-tetramethylbenzene are detected by GC/MS (Scheme 7). ${ }^{16}$ 


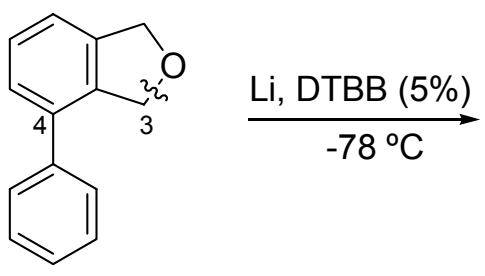

29

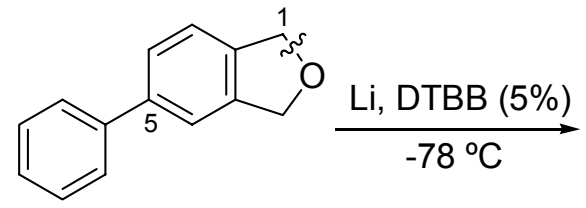

32<smiles></smiles>

35

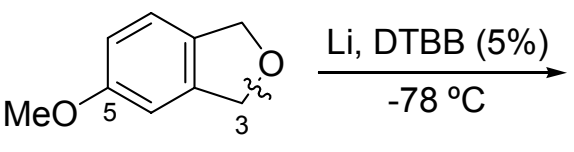

38<smiles>CCc1c(CO)cccc1-c1ccccc1</smiles>

30<smiles>OCc1cccc(-c2ccccc2)c1CF</smiles>

31 (32-95\%)

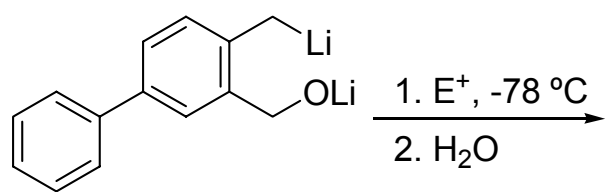

33<smiles>COc1cccc(CCl)c1COCl</smiles>

36<smiles>OCc1cc(-c2ccccc2)ccc1CF</smiles>

34 (18-95\%)<smiles>COc1cccc(CF)c1CO</smiles>

$37(40-50 \%)$

$$
\left[\mathrm{E}^{+}=\mathrm{H}_{2} \mathrm{O}, \mathrm{Bu}^{\mathrm{t}} \mathrm{CHO}, \mathrm{PhCHO}, \mathrm{Me}_{2} \mathrm{CO}, \mathrm{Et}_{2} \mathrm{CO}\right]
$$

\section{Scheme 6}

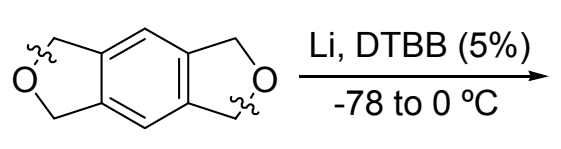

41<smiles>OCc1cc2c(cc1CCl)COC2</smiles>

42<smiles>OCc1cc(CCl)c(CO)cc1CCl</smiles>

43<smiles>OCc1cc(CO)c(CO)cc1CO</smiles>

\section{Scheme 7}




\subsection{Lithiation of halophthalans}

The treatment of halophthalans $\mathbf{4 6}, \mathbf{4 9}$ and $\mathbf{5 2}$ with a THF solution of lithium naphthalene (1:2.1 molar ratio) in THF at $-78{ }^{\circ} \mathrm{C}\left(0{ }^{\circ} \mathrm{C}\right.$ for the fluoro derivative 52), followed by reaction with an electrophile at low temperature gave, after hydrolysis with water, compounds $\mathbf{4 8 , 5 1}$ and $\mathbf{5 4}$, respectively (Scheme 8). Halogen-lithium exchange took place in the case of bromo and chloro derivatives 46 and 49 , respectively, leading to the aryllithium intermediates 47 and 50 , however, 4-fluorophthalan (52) undergoes selective reductive cleavage at C(3)-O benzylic carbon-oxygen bond, leading to the dilithium derivative $\mathbf{5 3}$ (Scheme 8). ${ }^{17}$ This completely different behavior can be explained taking into account halogen-carbon bond energies, because the fluorine-carbon bond is stronger than chlorine- and bromine-carbon bonds.<smiles>Brc1cccc2c1COC2</smiles>

46<smiles>Clc1ccc2c(c1)COC2</smiles>

49

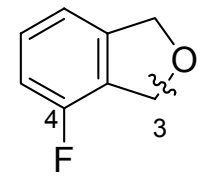

52

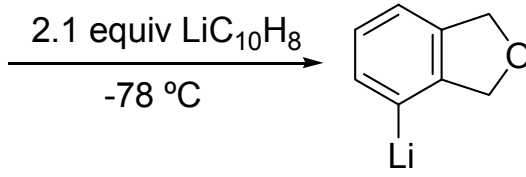

47
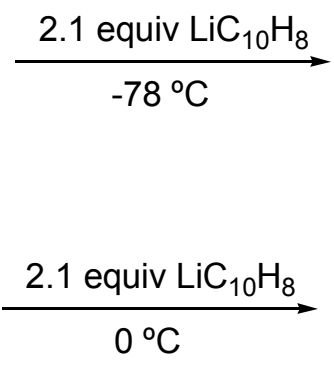

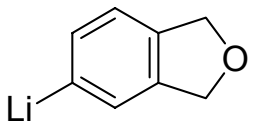

50<smiles>Fc1cccc(CCl)c1CCl</smiles>

53
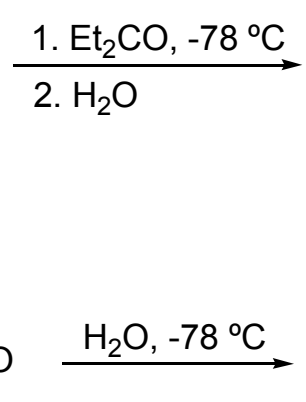

$\stackrel{\mathrm{H}_{2} \mathrm{O},-78^{\circ} \mathrm{C}}{\longrightarrow}$

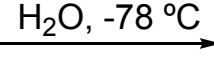

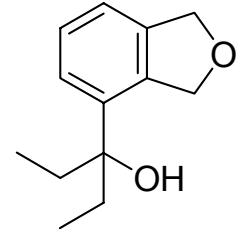

$48(30 \%)$

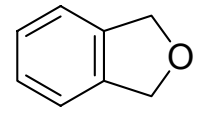

$51(>95 \%)$

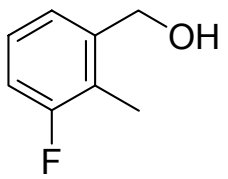

54 (>95\%)

\section{Scheme 8}

\subsection{Regiochemistry of the reductive opening lithiation of substituted phthalans}

The reductive cleavage at the benzylic carbon-oxygen bond in phthalan derivatives $\mathbf{2 4}$ (Scheme 5), 29, 32, 35, 38 (Scheme 6) and $\mathbf{5 2}$ (Scheme 8) takes place at the position bonded to the carbon of the aromatic ring with the higher electron density in the intermediate anion radical (one electron transfer) or dianion (two- electron transfer). ${ }^{18}$ The semi-empirical PM3 calculations of the Mulliken charges of the dianions 55-60 (Chart 1) resulting from a two-electron transfer to compounds 24, 29, 32, 35, 38 and 52, respectively, are shown in Chart 1. The reductive cleavage in these dianions occurs predominantly at the oxygen-benzylic carbon bond which is attached to the aromatic carbon atom with the highest electron density. This statement is true in the case of all the previously mentioned phthalan derivatives but not for the methoxy derivative $\mathbf{3 5}$ (dianion 58, Chart 1). Thus, taking into account the electron density both in the dianion and in the radical 
anion (which are in agreement), it is possible to explain the regiochemistry of the reductive opening lithiation of substituted phthalans. ${ }^{16,17}$
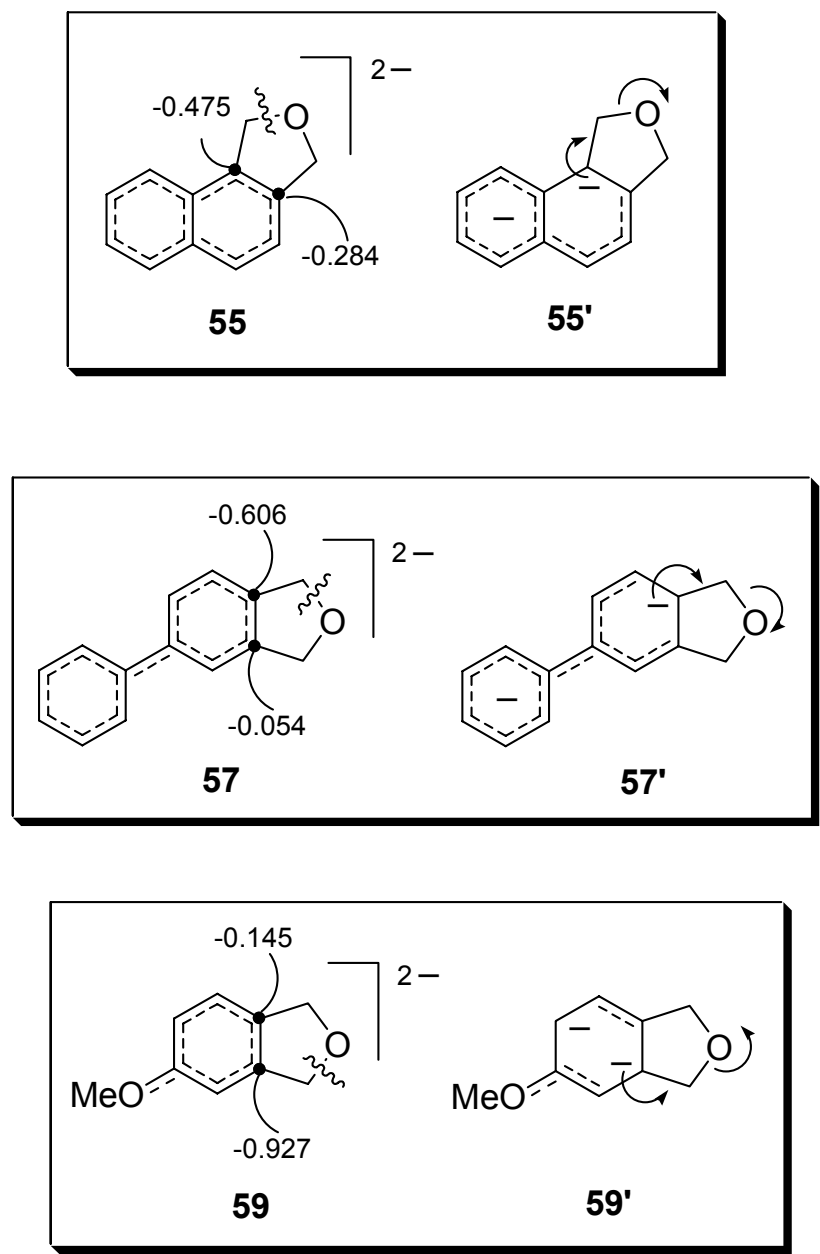
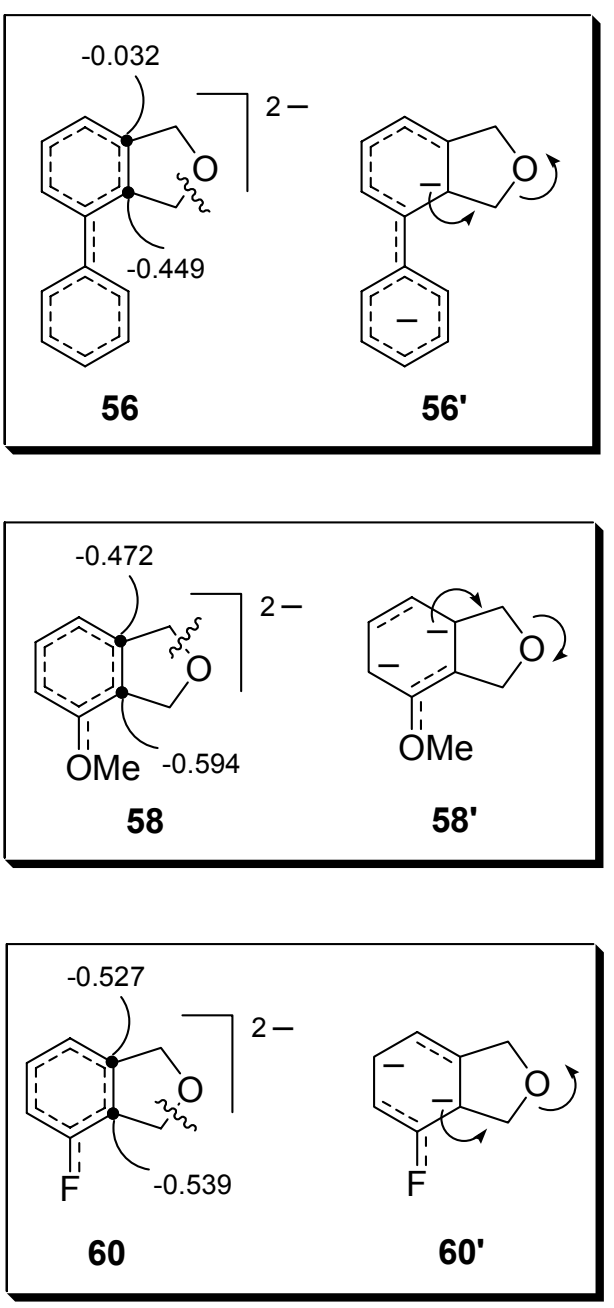

\section{Chart 1}

\subsection{Lithiation of cyclic acetals: synthesis of isochromans and naphthoxepines}

The reaction of cyclic acetals 61 or 64 (easily prepared from the corresponding diol and a carbonyl compound $\left.\mathrm{R}^{1} \mathrm{R}^{2} \mathrm{CO}\right)$ with an excess of lithium powder (1:14 molar ratio) and a catalytic amount of DTBB (1:0.1 molar ratio; $5.0 \mathrm{~mol} \%)$ in THF at temperatures ranging between -78 and $-60{ }^{\circ} \mathrm{C}$ for $5 \mathrm{~h}$ led, after hydrolysis with water, to the corresponding diols 62 and 65 , respectively, in moderate yields (Scheme 9). The cyclization of diols 62 and 65 under acidic conditions gave isochroman 63 and naphthoxepine derivatives 21, respectively (Scheme 9). ${ }^{17}$ 
<smiles>[R]C1([R])OCc2ccccc2CO1</smiles>

61

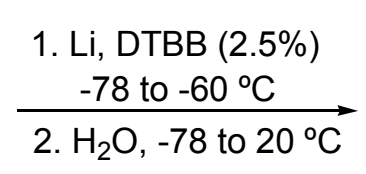

2. $\mathrm{H}_{2} \mathrm{O},-78$ to $20^{\circ} \mathrm{C}$<smiles>[R]C([R])(O)Cc1ccccc1CO</smiles>

$62(40-74 \%)$
$\underset{\mathrm{H}_{3} \mathrm{PO}_{4}(85 \%)}{\stackrel{115^{\circ} \mathrm{C}}{\longrightarrow}}$<smiles>[R]C1([R])Cc2ccccc2CO1</smiles>

63 (48->95\%)<smiles>[R]C1([R])OCc2cccc3cccc(c23)CO1</smiles>

64
1. Li, DTBB $(2.5 \%)$
$\frac{-78 \text { to }-60{ }^{\circ} \mathrm{C}}{\text { 2. } \mathrm{H}_{2} \mathrm{O},-78 \text { to } 20^{\circ} \mathrm{C}}$

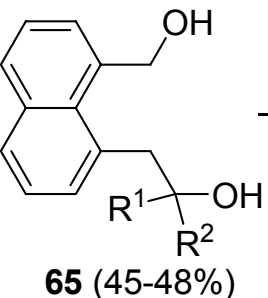

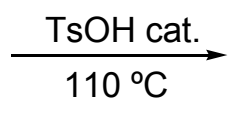

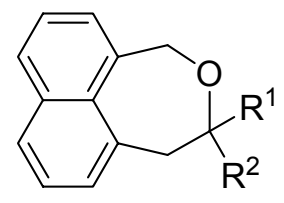

$21(>95 \%))$

$\left[\mathrm{R}^{1} \mathrm{R}^{2} \mathrm{CO}=\mathrm{CH}_{3}\left(\mathrm{CH}_{2}\right)_{7} \mathrm{CHO}, \mathrm{Ph}\left(\mathrm{CH}_{2}\right)_{2} \mathrm{CHO}, \mathrm{PhCHO}, \mathrm{Me}_{2} \mathrm{CO}, \mathrm{MeCOEt}, \mathrm{Et}{ }_{2} \mathrm{CO},\left(\mathrm{CH}_{2}\right)_{5} \mathrm{CO}\right]$

\section{Scheme 9}

Concerning a possible mechanistic pathway for the formation of compounds $\mathbf{6 3}$ and 21, it could be possible that in the first step, a benzylic cleavage takes place, giving dianionic intermediates of the type I and IV, respectively. These intermediates could afford either (a) directly the di-alcoholates II and $\mathbf{V}$, which are the precursors after hydrolysis with water of the final diols 62 and 65, respectively, or (b) complexes of type III and VI between a benzylic dianion and a carbonyl compound generated by an elimination from intermediates $\mathbf{I}$ and $\mathbf{I V}$, respectively (Chart 2).

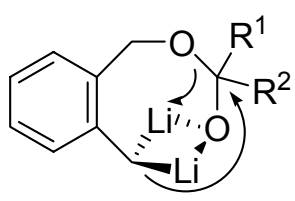

I<smiles></smiles>

IV<smiles>[R]C([R1])(O)Cc1ccccc1CO</smiles>

II

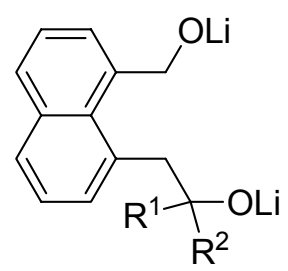

V

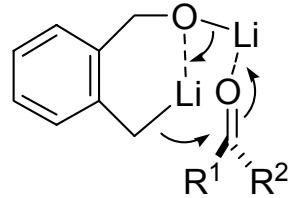

III

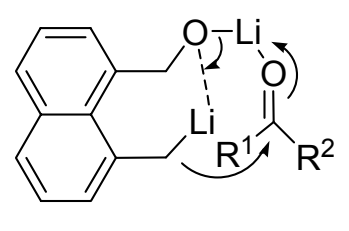

VI

\section{Chart 2}




\section{Conclusions}

From the results presented in this account we conclude that the reductive ring-opening of different benzo- fused heterocycles using an arene-catalyzed lithiation is a versatile methodology that allows the generation of several functionalized organolithium compounds. The reaction of these intermediates with electrophilic reagents leads to polyfunctionalized molecules, which in the case of using carbonyl compounds as electrophiles are adequate precursors for new series of homologated heterocycles.

\section{Acknowledgements}

This work was generously supported by the Spanish Ministerio de Educación y Ciencia (MEC; grant no. CTQ2004-01261 and CONSOLIDER INGENIO 2010/CSD2007-00006) and the Generalitat Valenciana (GV; grants no. GRUPOS05/052 and GRUPOS05/058).

\section{References and Footnotes}

1. For reviews on functionalized organolithium compounds, see: (a) Nájera, C.; Yus, M. Trends Org. Chem. 1991, 2, 155. (b) Nájera, C.; Yus, M. Org. Prep. Proc. Int. 1995, 27, 383. (c) Nájera, C.; Yus, M. Recent Res. Dev. Org. Chem. 1997, 1, 67. (d) Yus, M.; Foubelo, F. Rev. Heteroatom Chem. 1997, 17, 73. (e) Nájera, C.; Yus, M. Curr. Org. Chem. 2003, 7, 867. (f) Nájera, C.; Sansano, J. M.; Yus, M. Tetrahedron 2003, 59, 9255. (g) Chinchilla, R.; Nájera, C.; Yus, M. Chem. Rev. 2004, 104, 2667. (h) Chinchilla, R.; Nájera, C.; Yus, M. Tetrahedron 2005, 61, 3139. (i) See also the special issue of Tetrahedron Symposium in Print (Eds.: Nájera, C; Yus, M.) devoted to 'Functionalised Organolithium Compounds', Tetrahedron 2005, 61, issue no. 13. (j) Yus, M.; Foubelo, F. In Handbook of Functionalized Organometallics; Knochel, P., Ed.; Wiley-VCH: Weinheim, 2005; Chapter 2.

2. For monographs, see: (a) Wakefield, B. J. Organolithium Methods; Academic Press: London, 1988. (b) Sapse, A. M.; von Ragué Schleyer, P., Eds. Lithium Chemistry: A Theoretical and Experimental Overview; J. Wiley \& Sons: New York, 1995. (c) Gray, M.; Tinkel, M.; Snieckus, V. In Comprehensive Organometallic Chemistry II; Abel, E. W.; Stone, F. G. A.; Wilkinson, G.; McKillop, A., Eds.; Pergamon: Oxford, 1995; Vol. 11, pp. 192. (d) Clayden, J. Organolithiums: Selectivity for Synthesis; Pergamon: Oxford, 2002. For a review on metal-promoted dehalogenation, see: (e) Alonso, F.; Beletskaya, I. P.; Yus, M. Chem. Rev. 2002, 102, 4009.

3. For reviews, see: (a) See reference 1d. (b) Yus, M.; Foubelo, F. Targets in Heterocyclic Systems 2002, 6, 136. (c) Yus, M. Pure Appl. Chem. 2003, 75, 1453. (d) Yus, M.; Foubelo, F. Adv. Heterocycl. Chem. 2006, 91, 135. 
4. Almena, J.; Foubelo, F.; Yus, M. Tetrahedron 1995, 51, 3351.

5. Azzena, U.; Demartis, S.; Fiori, M. G.; Melloni, G.; Pisano, L. Tetrahedron Lett. 1995, 36, 8123.

6. Yus, M.; Gomis, J. Eur. J. Org. Chem. 2003, 2043.

7. Yus, M.; Gomis, J. Tetrahedron Lett. 2001, 42, 5721.

8. Yus, M.; Gomis, J. Eur. J. Org. Chem. 2002, 1989.

9. Pastor, I. M.; Yus, M. Tetrahedron Lett. 2000, 41, 1589.

10. Pastor, I. M.; Yus, M. Tetrahedron 2001, 57, 2371.

11. Almena, J.; Foubelo, F.; Yus, M. Tetrahedron 1995, 51, 3365.

12. Foubelo, F.; Yus, M. Tetrahedron Lett. 2001, 42, 2469.

13. Foubelo, F.; Moreno, B.; Soler, T.; Yus, M. Tetrahedron 2005, 61, 9082.

14. Foubelo, F.; Moreno, B.; Yus, M. Tetrahedron Lett. 2004, 45, 8983.

15. Foubelo, F.; Moreno, B.; Yus, M. Tetrahedron 2004, 60, 4655.

16. Foubelo, F.; García, D.; Moreno, B.; Yus, M. Tetrahedron Lett. 2007, 48, 3379.

17. Foubelo, F.; García, D.; Yus, M. Unpublished results.

18. Paddon, C. A.; Bhatti, F. L.; Donohoe, T. J.; Compton, R. G. Chem. Commun. 2006, 3402. 